\title{
Como e o que os professores aprendem: uma perspectiva em transformação ${ }^{1}$
}

Lee S. Shulman*

Judith H. Shulman **

* (Universidade Stanford, Palo Alto, Califórnia, EUA)

** (WestEd², São Francisco, Califórnia, EUA)
Resumo: Com base na experiência do programa "Promover uma comunidade de aprendizes", propõe-se, neste artigo, uma estrutura conceitual para aprofundar a compreensão sobre os distintos modos pelos quais os professores aprendem e, em especial, aprendem a ensinar em diferentes comunidades e contextos. Ao apresentar um novo modelo, busca-se refletir criticamente sobre os desafios encontrados pelos professores, comunidades de professores, instituições formadoras, programas e políticas que tenham no cerne 0 desenvolvimento profissional docente.

Palavras-chave: Formação de professores. Política educacional. Ensino. Didática.

Neste artigo, aprofundamos nosso esforço em criar uma estrutura conceitual para descrever e analisar os desafios relativos à formação de professores a fim de que estes sejam capazes de criar, manter e ensinar em uma "comunidade de aprendizes". Em particular, oferecemos uma nova estrutura para conceituar como os professores aprendem e se desenvolvem em diferentes comunidades e contextos. Essa concepção permite-nos entender as várias respostas dos professores ao processo de aprender a ensinar, como está descrito no programa "Promover uma comunidade de aprendizes" $(\mathrm{PCA})^{3}$. 0 modelo ilustra o processo de

Lee S. Shulman; Judith H. Shulman. "How and What Teachers Learn: a Shifting Perspective". Texto publicado originalmente em Journal of Curriculum Studies, v. 36, n. 2, p. 257-271, 2004. Direitos autorais (2004) reservados para Taylor \& Francis Ltd. Traduzido e publicado com autorização. Tradução de Leda Beck e revisão técnica de Paula Louzano e Bárbara Barbosa Born a partir da edição publicada em The Journal of Education, v. 189, n. 1/2, p. 1-8, 2008/2009. [N. de E.]

WestEd é uma organização sem fins lucrativos, com sede em São Francisco, na Califórnia, que funciona como um órgão de pesquisa, desenvolvimento e serviços na área de educação e em outros setores. [N. de T.] No original, em inglês, "Fostering a Community of Learners" (FCL). [N. de E.] 
interação entre estudantes e professores, nas aprendizagens institucionais ou do programa, bem como o ambiente necessário para a criação de políticas públicas que são cruciais para o sucesso de reformas pautadas em pesquisas, tal qual o PCA.

Modelos e teorias emergem de muitas maneiras. 0 modelo de que trata este artigo nasceu durante um período em que trabalhávamos com um grupo das universidades Stanford e Vanderbilt, e com a Universidade da Califórnia em Berkeley, para "reinventar" e ampliar o modelo "Promover uma comunidade de aprendizes" (PCA), de Brown e Campione (1992, 1996). Nosso desafio era criar uma experiência formativa para os professores que os preparasse para criar, manter e ensinar em uma "comunidade de aprendizes", como previsto e definido na concepção do $\mathrm{PCA}^{4}$. $\mathrm{O}$ trabalho era muito desafiador e percebíamos constantemente quão diferentes entre si eram os professores com os quais trabalhávamos, e especialmente o quanto eles variavam com relação à facilidade ou à dificuldade com que essas novas ideias eram aceitas e postas em prática em seu ambiente de trabalho. Os artigos de Mintrop (2004), Rico e Shulman (2004), Sherin et al. (2004) e Whitcomb (2004) nesta edição da revista ${ }^{5}$ avaliam um aspecto desse trabalho: como a formação de professores para trabalhar essas novas ideias dependiam da disciplina que ensinavam. Este artigo não relata esse projeto propriamente dito, mas sim o trabalho conceitual que enfrentamos para dar sentido ao projeto.

Como sempre acontece, o trabalho teórico foi estimulado por um conjunto específico de experiências intrigantes. 0 estímulo inicial ocorreu nas longas visitas a salas de aula, durante vários dias. À medida que observávamos esses ambientes, ficávamos impressionados como duas professoras de $8^{0} \underline{0}$ ano podiam ser completamente diferentes uma da outra. Elas trabalhavam como uma equipe do programa "Escolas para pensar" (EPP) ${ }^{6}$, uma iniciativa muito próxima do PCA. Uma delas era uma professora de matemática e ciências relativamente inexperiente, que parecia ter um conhecimento disciplinar mais profundo na área de ciências. Ela também tinha crenças fortemente construtivistas sobre ensino e aprendizagem em sua área de conhecimento, visões bastante claras sobre como o ensino EPP poderia servir para integrar seus entendimentos cognitivos dispersos sobre ensino

No texto que segue, sempre nos referimos a "um professor PCA" porque o programa "Promover uma Comunidade de Aprendizes" (PCA) é o contexto em que fizemos esse trabalho. Afirmamos, porém, que as dimensões utilizadas aqui podem ser aplicadas às características universais do ensino eficaz e seu desenvolvimento.

Nota do editor da Journal of Education: Journal of Curriculum Studies, v. 36, n. 2, 2004.

No original, "Schools for Thought" (STF). [N. de E.] 
e aprendizagem - assim como um sistema de crença sobre por que esse modelo de ensino era preferível às formas mais passivas de aprender - e um alto nível de motivação para criar tais ambientes em sua própria sala de aula. Nesses termos, ela parecia ser a candidata ideal para um ensino PCA/ EPP. No entanto, por causa de sua inexperiência, ela carecia das habilidades práticas de planejamento e desenvolvimento de projetos instrucionais de que precisaria para criar materiais e atividades curriculares necessários para concretizar suas visões, mesmo na sua área de especialidade. Ela também parecia carecer de competências de gestão e organização da sala de aula. Para nós, ela se tornou um caso significativo.

Sua colega de escola era muito diferente. Ali estava uma professora veterana que parecia ter as habilidades organizacionais para gerenciar a complexidade do ensino EPP em sala de aula, mas que ainda estava desenvolvendo sua visão e compreensão do como (e do porquê) tais salas de aula deveriam ser daquela maneira. Diferentemente de sua colega mais jovem, os conceitos construtivistas de ensino e aprendizagem eram novidade para ela. Ela tinha, por causa de sua experiência, as habilidades práticas pedagógicas e de gestão para criar um ambiente do tipo PCA/EPP, mas suas visões desse ensino e sua compreensão das teorias que embasavam esse tipo de pedagogia eram superficiais. Por outro lado, como sua colega menos experiente, ela também parecia altamente motivada a criar e manter uma sala de aula EPP.

Teoria começa com reflexão: como e por que essas duas professoras, pensamos, eram tão diferentes? Sentimos a necessidade de desenvolver uma linguagem teórica para descrever as diferenças entre elas e para explicitar suas capacidades. Queríamos que essa teoria fosse baseada na linguagem da aprendizagem do professor, porque nosso papel no projeto maior era analisar como os professores aprendem a ensinar em tais contextos. Uma formulação teórica era necessária para identificar os componentes da capacidade dos professores para ensinar (e para sugerir como essas funções se relacionavam entre si), assim como as condições sob as quais eles poderiam mudar e desenvolver-se como professores.

Em nossos estudos anteriores sobre como os professores aprendem, um de nós (Lee S. Shulman) empregou construtos que eram estritamente cognitivos e individuais, como conhecimento pedagógico do conteúdo e ação e raciocínio pedagógicos, e ficou satisfeito com a distinção entre diferentes tipos de conhecimento sobre o ensino (SHULMAN, 1986, 1987)7. Essas concepções

Este último texto (SHULMAN, 1987) foi recentemente traduzido para o português e publicado em volume anterior desta revista. Cf. "Conhecimento e ensino: fundamentos 
estavam estreitamente vinculadas com a centralidade de cada disciplina e com as diferenças específicas das disciplinas no que dizem respeito ao ensino e à aprendizagem, que são o tópico dos artigos anteriores nesta edição do Journal of Curriculum Studies.

Em trabalho anterior sobre aprendizado docente baseado em estudo de caso, o outro membro da equipe (Judith H. Shulman) empregou modelos teóricos que descrevem como os professores aprendem por meio de reflexões críticas estruturadas sobre suas próprias práticas, exemplificadas nos estudos de caso (SHULMAN, 2002, 2003). Esse trabalho prestou muito menos atenção à importância da especificidade das disciplinas e focou mais diretamente na maneira como os professores podem transformar suas experiências individuais em conceitos mais generalizáveis via reflexão individual e coletiva, além da leitura e escrita de estudos de caso.

Mas nenhuma dessas concepções parecia bastante abrangente para dar conta daquilo que estávamos observando. Em vez de tentar reformular nossos velhos modelos, encaramos o desafio de desenvolver um novo esquema conceitual, começando do zero. Para o nosso trabalho em "Promover comunidades de professores aprendizes" $(\mathrm{PCPA})^{8}$, como apelidamos nossa parte na iniciativa maior, reconhecemos a necessidade de estruturar uma concepção mais abrangente da aprendizagem e da formação de professores em diferentes comunidades e contextos.

COMUNIDADES DE APRENDIZAGEM PARA PROFESSORES: UM NOVO MODELO

Como podemos analisar as características da aprendizagem docente de maneira que possa descrever, explicar e, em última análise, guiar a formação de professores que sejam capazes de ensinar em salas de aula claramente embasadas por uma rica teoria, abertas a diversas estratégias e ao mesmo tempo rigorosas no conteúdo a ser trabalhado, como previsto pelo PCA? Partimos do pressuposto de que um professor competente é membro de uma comunidade profissional e está preparado, disposto e capacitado para ensinar e para aprender com suas experiências práticas. Portanto, os elementos que aparecem na teoria são: Preparado (tem visão), Disposto (tem motivação), Capacitado (tanto sabendo, como sendo capaz de "fazer"), Reflexivo

para a nova reforma”. Cadernos Cenpec, v. 4, n. 2, p. 196-229, dez. 2014. Disponível em: 〈http://cadernos.cenpec.org.br/cadernos/index.php/cadernos/article/view/293〉. Acesso em: 7 nov. 2016. [N. de E.]

8 “Fostering Communities of Teachers as Learners" (FCTL), no original. [N. de E.] 
(aprende com a experiência) e Comunitário (agindo como membro de uma comunidade profissional). Cada uma dessas dimensões envolve aspectos do desenvolvimento pessoal/profissional e pode conectar-se com parte de um currículo de formação docente ou de formação continuada. Nesse modelo, teríamos professores:

- preparados para seguir uma visão de salas de aula ou escolas que constituem, por exemplo, comunidades de aprendizagem;

- dispostos a despender a energia e a persistir para colocar em prática esse tipo de ensino;

- que compreendem os conceitos e princípios necessários para esse tipo de ensino;

- capazes de se engajar nas complexas formas de práticas pedagógicas e organizacionais necessárias para transformar suas visões, motivações e compreensões em realidade pragmática e funcional; capazes de aprender com as experiências, as próprias e as de outrem, por meio de reflexão ativa sobre suas ações e suas consequências; e

- capazes e experientes em trabalhar como membros de uma comunidade de aprendizagem e/ou na formação de tais comunidades em seus contextos de atuação docente.

$\mathrm{Na}$ forma de lista, o novo modelo sustenta que as características do desenvolvimento do professor competente, e, portanto, da aprendizagem docente, são: visão, motivação, compreensão, prática, reflexão e comunidade.

Intercalando essas características, podemos descrever mais precisamente os professores, como aqueles que observamos no EPP e também em nosso trabalho anterior, em diferentes etapas ou posições no processo de aprender a ensinar dessa forma. Podemos caracterizar os professores que estão prontos para se engajar no ensino construtivista (ou em outras formas de ensino), mas a quem falta disposição, conhecimento e habilidade para fazêlo. Trabalhamos com professores que entendem os princípios, mas não têm a disposição para segui-los ou a habilidade para implementá-los. Podemos até imaginar professores que têm as habilidades requeridas, mas a quem falta a compreensão de seu propósito ou da lógica por trás do propósito e, portanto, não têm vontade de aplicar essas habilidades e não se inspiram com a visão de educação em que eles são o ponto central. Podemos certamente conceber aqueles que têm todas as capacidades individuais, mas não participam do tipo de comunidade de professores que torna possível transformar a intenção em realidade. 
Agora vamos examinar cada um desses cinco primeiros construtos como parte de um modelo mais abrangente (ver Figura 1). Quais são as características (pensamentos, ações, disposições, valores, compromissos, paixões, compreensões, habilidades etc.) de um professor competente? Depois disso, voltaremos a uma discussão sobre a sexta característica do professor competente, a da comunidade.

Preparado: o desenvolvimento da visão

Um professor precisa estar pronto para ensinar. Por exemplo, no programa PCA, um professor competente deve desenvolver uma visão específica de ensino e aprendizagem; de processo de aprendizagem (ativo, construtivo, metacognitivo) em termos disciplinar e interdisciplinar; de uma sala de aula onde um leque de atividades individuais e de grupo, consistentes com os princípios do PCA, deve ser desenvolvido. Ele está disposto a pensar no ensino como um processo diferente de "dar aula" e na aprendizagem como um processo diferente de repetir ou reafirmar o dito pelo professor. Um professor PCA está, em termos ideológicos, profundamente insatisfeito com o status quo. Uma visão altamente desenvolvida e articulada serve como meta, para a qual deve ir o desenvolvimento do professor, e também como um padrão para avaliar suas próprias crenças e ações, bem como as de seus colegas. Discrepâncias entre a visão e a atuação podem criar a motivação para aprender ou - se forem muito grandes - podem desencorajar a aprendizagem e substituir a esperança pelo desânimo (HAMMERNESS, 2006).

Figura 1 - Nível individual da análise.

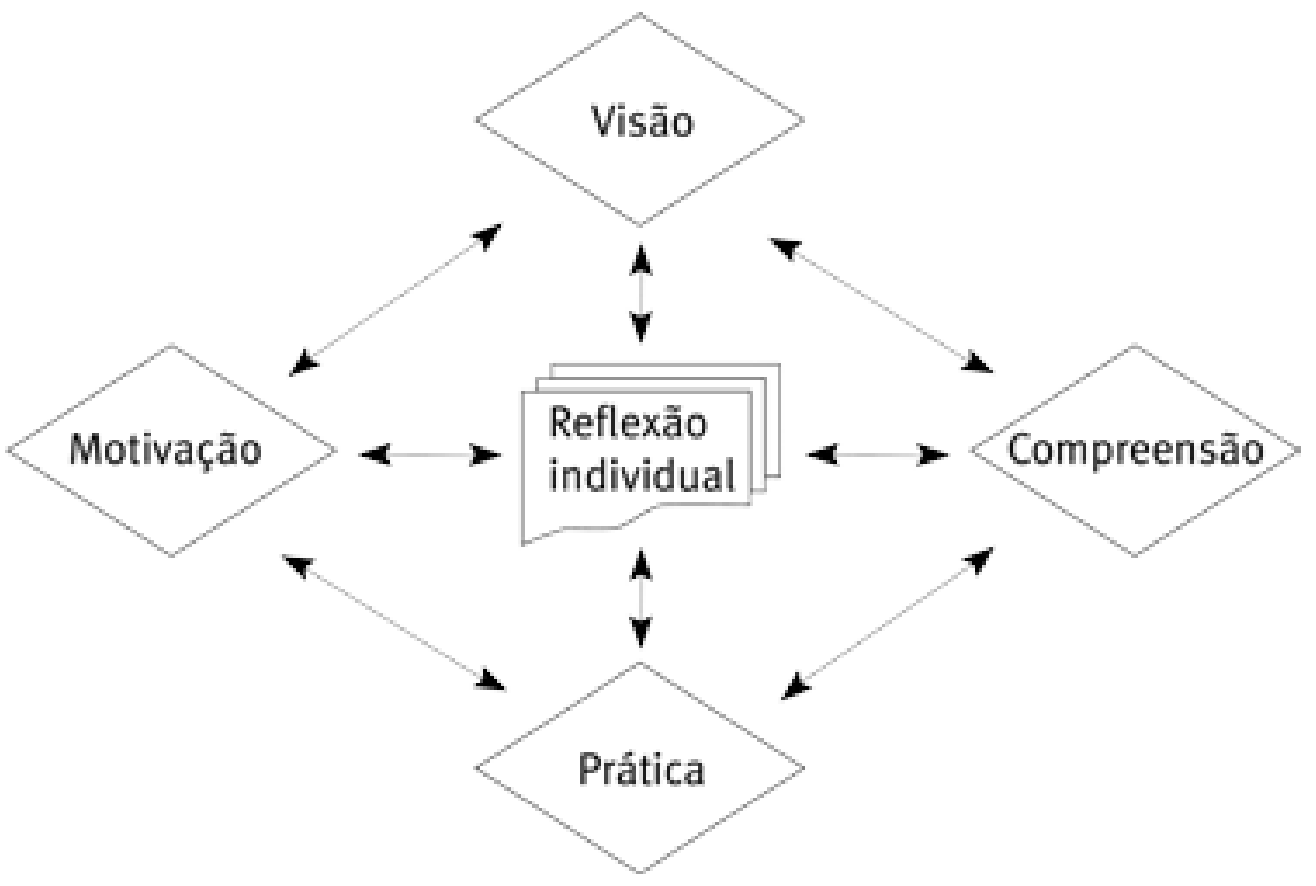

Fonte: Elaborada pelos autores. 
Com relação ao desenvolvimento de visões de ensino e aprendizagem que determinam a prontidão dos professores para aprender as abordagens PCA, podemos nos perguntar: que tipo de experiências devem ser propiciadas na formação de professores para aumentar essa prontidão? Como uma visão pode ser guiada, aumentada, diferenciada e aprofundada? Há estágios, níveis ou categorias de prontidão? Se há, como podemos avaliá-las, medilas, reconhecê-las? Há diferenças importantes entre alguns estados de maturação, como "em transição", “com dificuldades” ou "maduros”? Como os professores poderiam reconhecer em si mesmos a sua prontidão e refletir individual e coletivamente sobre suas próprias visões do desejável e do possivel?

\section{Disposto e motivado}

Para desenvolver uma nova visão do ensino, o professor pode encontrar professores mais experientes, ler estudos de caso, assistir a vídeos de aulas, discutir com os pares, estudar artigos acadêmicos etc. E mesmo que esteja bastante decepcionado com o status quo, ele pode não querer colocar em prática essa nova visão, pode estar pouco motivado para a mudança, ter pouco apoio em seu ambiente de trabalho ou de seus pares para se arriscar a abandonar práticas tradicionais ou para fazer o esforço necessário para mudar, e assim por diante. Costumamos fazer uma analogia com alguém que tem uma visão de parar de fumar, alimentar-se de maneira mais saudável ou começar a fazer exercícios regularmente, mas a quem falta a vontade ou o ambiente de apoio para colocar em prática essa visão. Esse quadro contrasta, por exemplo, com o clássico caso da “Professora Oublier” de Cohen (1990), que parece querer ensinar uma matemática que seja entendida pelos alunos, mas aparentemente carece de uma visão suficientemente bem desenvolvida das práticas desejáveis e suas lógicas subjacentes para fazer mudanças inteligentes e eficazes.

Podemos fazer, para esta categoria de disposição, o mesmo tipo de perguntas que fizemos para a primeira categoria conceitual. Há estágios, níveis ou categorias de motivação, compromisso ou disposição? Que tipos de formação de professores, tais como cursos, oficinas, grupos de pesquisa, estudos de caso, desenvolvimento de uma comunidade de professores, reestruturação da escola, rede de professores, suporte administrativo, dissonância cognitiva etc., seriam úteis para promover esse desenvolvimento motivacional? De onde vem a vontade de mudar? Em que medida a "disposição" é uma categoria interna e em que medida ela resulta da gestão de incentivos, prêmios e pressões externas? 
Um professor competente precisa entender o que deve ser ensinado, assim como precisa saber como ensinar. Na linguagem do Conselho Nacional para os Padrões de Ensino Profissional (1992), os professores devem saber e devem ser capazes de fazer. Portanto, para ensinar de maneira compatível com o PCA, um professor precisa entender tanto os princípios dos problemas, tópicos e questões do currículo de sua disciplina como os princípios do PCA, sua lógica subjacente, as relações entre eles e as características de sua instanciação bem-sucedida. Além de saber, ele precisa ser capaz de fazer, de se engajar nas práticas necessárias para transformar a visão e a concepção em ação.

Compreensão

Esta categoria da “compreensão" é bem grande. Inclui muito do que estudamos nos últimos 20 anos em nossa pesquisa sobre conhecimento e entendimento do professor. Com efeito, dentro dessa categoria de "compreensão" podemos encontrar muitos dos elementos que são hoje comuns nos padrões que compõem a base de conhecimento necessária para a docência. Exemplos incluem:

- Conhecimento disciplinar/de conteúdo/interdisciplinar.

- Compreensão do currículo (que inclui onde podem ser estabelecidas as junções entre os tópicos disciplinares e interdisciplinares, da mesma forma que se juntam as peças de um quebra-cabeça?).

- Conhecimento do conteúdo pedagógico para colocar em prática o PCA (e conhecimento de casos em múltiplas instâncias e práticas).

- Organização e gestão de sala de aula (tanto proativa como reativa, com foco especial na compreensão dos princípios de múltiplas formas de trabalho em grupo).

- Avaliação de aprendizagem em sala de aula.

- Comunidade competente: micro - na sala de aula; midi - na escola ou rede de escolas; mini - na comunidade local; macro - na profissão ou dentro do contexto mais amplo de esforços de reforma nas políticas públicas.

- Entender os alunos intelectual, social, cultural e pessoalmente com uma perspectiva de desenvolvimento integral.

A compreensão para um ensino compatível com o PCA também pode ser dividida em mais quatro processos constituintes:

- Entender o currículo e seu conteúdo disciplinar de maneira profunda, 
flexível e geradora.

- Compreender os princípios pedagógicos que embasam o PCA e ser capaz de projetar e implementar um ensino consistente com esses princípios.

- Distinguir práticas de ensino compatíveis com o PCA de práticas incompletas, das não implementações e das mutações letais, ou seja, saber imediatamente do que se trata ao enxergar a prática.

- Avaliar, nos alunos, as variações na aprendizagem, na interação entre eles e no desenvolvimento que resulta (ou deveria resultar) do ensino PCA.

Tomadas juntas, essas são as expectativas para o desenvolvimento do conhecimento pedagógico do conteúdo para esse tipo de ensino. Nos artigos anteriores, os autores examinaram em que medida esses tipos de conhecimentos e habilidades específicas de cada disciplina podem explicar variações no desempenho do professor.

Todos esses elementos da compreensão podem ser analisados em termos de processos pedagógicos e de aprendizagem, características específicas dos conceitos e do trabalho com cada disciplina, e a partir da fusão apropriada do pedagógico com as dimensões substantivas. Isto é, um professor pode entender os princípios e as práticas do PCA, mas implementá-los a serviço de concepções disciplinares empobrecidas; ou ele pode ter um profundo conhecimento conceitual sem uma compreensão dos princípios pedagógicos e de ensino por trás do PCA. Uma professora pode entender quais são os princípios de verificação de aprendizagem do aluno ou da avaliação do portfólio para uma aprendizagem autêntica, mas carecer da percepção disciplinar necessária para eficazmente realizar avaliações de uma disciplina em particular ou mesmo de maneira interdisciplinar (ou ainda avaliar os resultados dessas avaliações). Pode-se estar engajado na intenção de colocar em prática o ensino PCA e não se perceber as diferenças significativas entre o que os próprios alunos estão fazendo e aprendendo e os tipos de práticas de fato esperadas pelo PCA.

Como com as dimensões anteriores, precisamos perguntar como identificar diferentes estágios ou níveis ou caminhos para a compreensão dos professores. Precisamos também perguntar que tipos de atividades de formação de professores promoverão os tipos certos de aprendizagem nesses docentes. 
Tendo discutido tanto a visão como a compreensão, agora vamos para o coração do ensino, que é a capacidade de ação inteligente e flexível. Um professor PCA competente não tem apenas a prontidão, a disposição e a compreensão do ensino PCA. Ele é também capaz de executar esse tipo de ensino, que é enormemente complexo na prática. Um profissional competente não é apenas alguém inspirado, esclarecido e motivado; ele também deve ser estar habilitado nas variedades da prática. 0 ensino PCA exige bastante dos professores no planejamento e adaptação do currículo, na gestão de múltiplas rotações que ocorrem simultaneamente em sala de aula, na avaliação formal e informal de compreensões e processos complexos entre alunos diversos, na integração de uma profunda compreensão disciplinar com necessidade de engajamento e interação entre os alunos, nos usos da tecnologia no dia a dia da sala de aula etc. Essa habilidade deverá desenvolver-se gradualmente, ao longo do tempo. Formadores de professores, tanto na formação inicial como continuada, precisam analisar como o desenvolvimento dessa habilidade pode ser identificado, estimulado, medido, corrigido e sustentado.

Todo tipo de ensino exige muito dos professores no momento da prática. 0 ensino PCA envolve ainda mais demandas, por causa da complexidade das rotinas simultâneas, do caráter exigente de cada uma das rotinas separadamente, do desafio de monitorar e ser capaz de atender alunos heterogêneos de maneira individual, de criar salas de aula que distribuem o conhecimento entre todos os alunos, e outras coisas do gênero.

A complexidade desse ensino torna seus resultados muito mais incertos e imprevisíveis do que os tipos mais estruturados de ensino direto. Por essa razão, é fundamental e necessário aprender e se adaptar a partir da experiência prática. Portanto, a análise crítica da própria prática e o exame crítico de quão bem os alunos responderam a essa prática são elementos centrais de qualquer modelo de ensino. No coração dessa aprendizagem está o processo da reflexão crítica.

Aprender com a experiência por meio da reflexão

Se o professor competente fosse meramente capaz de ter visão, motivação, compreensão e prática, ele ainda careceria da capacidade para aprender com a experiência e, portanto, da capacidade de transformar-se de maneira deliberada. Assim como os princípios do PCA enfatizam a importância, para os alunos PCA, dos processos metacognitivos como chave para a transferência 
e o monitoramento da compreensão, esses princípios também destacam a centralidade da reflexão entre os professores. Boa parte de nosso trabalho, tanto com professores novatos como com veteranos, apoia os esforços deles para se tornarem mais conscientes de seus próprios conhecimentos, práticas e disposições. Por meio da discussão do trabalho deles - do projeto de currículo, ensino e avaliação em sala de aula - e do desenvolvimento de portfólios de ensino, estudos de caso e discussões regulares sobre a prática, visamos melhorar as capacidades dos professores para aprender com suas próprias experiências e com as de outros professores. Um pressuposto central de nosso modelo de formação docente é que a reflexão é chave para a aprendizagem e o desenvolvimento do professor.

Durante os quatro anos de trabalho nesse projeto, um de nós (Judith $\mathrm{H}$. Shulman) reuniu professores novatos e experientes para refletir juntos sobre as suas experiências, para desenvolver estudos de caso a partir de suas práticas e para explorar o que poderia ser aprendido por eles e por outros professores a partir de suas experiências. Encontros regulares foram mantidos com os professores para promover e sustentar essa análise crítica do seu trabalho (SHULMAN et al., 1997). Essa abordagem também tem uma semelhança familiar aos estudos de Sherin (2001; SHERIN; HAN, 2004) sobre o uso de vídeos de aulas para apoiar a aprendizagem de professores com base em sua própria prática. Em quase todas as profissões que estudamos, as formas de reflexão e de análise crítica estruturadas são centrais, e essa centralidade é crucial.

Podemos resumir o modelo estrutural (ver Figura 1) ao afirmar que o professor competente integra visão, motivação, compreensão e prática na aplicação do ensino PCA, e aprende a melhorar o seu ensino por meio de reflexão ativa. Aplicar ou praticar o ensino compatível com o PCA demanda uma ação cuidadosa, reflexiva e deliberada. Podemos também usar o termo práxis para denotar uma forma de prática que é autoconsciente e crítica, baseada tanto em visão quanto em crenças ideológicas (como interdependência, respeito à diversidade e outras coisas do tipo).

De forma geral, podemos imaginar cinco grupos de atributos em torno dos quais se desenvolve o ensino competente:

- Um grupo cognitivo, que inclui discernir, entender e analisar.

- Um grupo de disposições, que inclui ter visão, acreditar e respeitar.

- Um grupo motivacional, que inclui querer mudar e persistir.

- Um grupo de práticas, que inclui agir, coordenar, articular e iniciar. 
- Um grupo reflexivo, que inclui avaliar, rever, autocriticar-se e aprender com a experiência.

Na próxima seção, discutimos a sexta característica do desenvolvimento do professor competente, que é a da comunidade. Ao fazê-lo, argumentamos pela importância de um grupo comunitário, que inclui deliberação, colaboração, ajuda mútua e expertise distribuída. Tomadas juntas, essas são as dimensões do ensino competente num ambiente de reforma rico em teoria, do qual o PCA é o principal exemplo. Elas também servem para definir os pontos focais de quaisquer esforços em educação ou formação docente dedicados a preparar os professores para trabalhar com eficácia no ambiente complexo, incerto e muitas vezes imprevisível das escolas.

\section{UNIDADE DE ANÁLISE: O INDIVÍDUO E A COMUNIDADE}

Roberto Merton, o ilustre sociólogo, observou que as pessoas dão forma a suas organizações e que essas organizações, por sua vez, dão forma às pessoas (MERTON, 1967). Em nossas discussões ao longo dos últimos anos, lutamos para discernir qual seria a melhor conceituação de nossos esforços. Em particular, vimo-nos entre as concepções do professor individual e sua aprendizagem, de um lado, e a comunidade de professores, de outro, como nossa unidade fundamental de análise. Isto é, até que ponto estamos analisando como professores individuais aprendem a se engajar no desenvolvimento de currículos e práticas de ensino, que é essencial para este tipo de ensino, e até que ponto estamos investigando a aprendizagem e a mudança nas comunidades de professores?

A máxima de Merton, porém, lembra-nos de que a dicotomia é enganadora. As duas dimensões estão em interação contínua e se determinam mutuamente. Todos os professores com quem trabalhamos são membros de um ou mais grupos ("comunidade" pode ser um nome inadequado em muitos casos) que influenciam suas crenças e suas práticas. No entanto, especialmente no caso de professores em formação (que estudam em faculdades e estagiam em escolas), suas comunidades de aprendizagem são finalmente substituídas por novas comunidades de ensino quando eles assumem seus primeiros papéis profissionais. Quanto da aprendizagem promovida em suas comunidades de aprendizagem anteriores será transferido para os novos cenários? Se a aprendizagem profissional está vinculada a comunidades específicas, o que acontece quando esse contexto muda?

Para mostrar a interação contínua entre os níveis de análise individual e 
comunitário, representamos o modelo estrutural de várias maneiras, cada uma delas visando a destacar diferentes aspectos das relações. A Figura 2 e a Figura 3 retratam os dois níveis de análise juntos, o individual e o comunitário. $\mathrm{Na}$ Figura 3, podemos ver como cada professor utiliza as suas próprias visões, motivações, compreensões e capacidades para desempenhar sua prática docente e para refletir sobre seu trabalho. Ao mesmo tempo, podemos conceber comunidades de professores em que visões compartilhadas (com frequência chamadas de mitos ou imagens religiosas, em outros contextos), compromissos comunitários, uma base compartilhada de conhecimento (que pode ser comum ou pode ser uma forma de expertise compartilhada), uma comunidade de práticas e rituais ou cerimônias estabelecidos para reflexão conjunta podem servir tanto para melhorar o desenvolvimento de certas práticas docentes, inibir ativamente o seu desenvolvimento ou ser neutra com respeito a elas. Como Merton afirma, os indivíduos contribuem para a formação de normas, incentivos e práticas da comunidade, enquanto a comunidade exerce suas influências nos indivíduos participantes.

Figura 2 - Nível comunitário da análise.

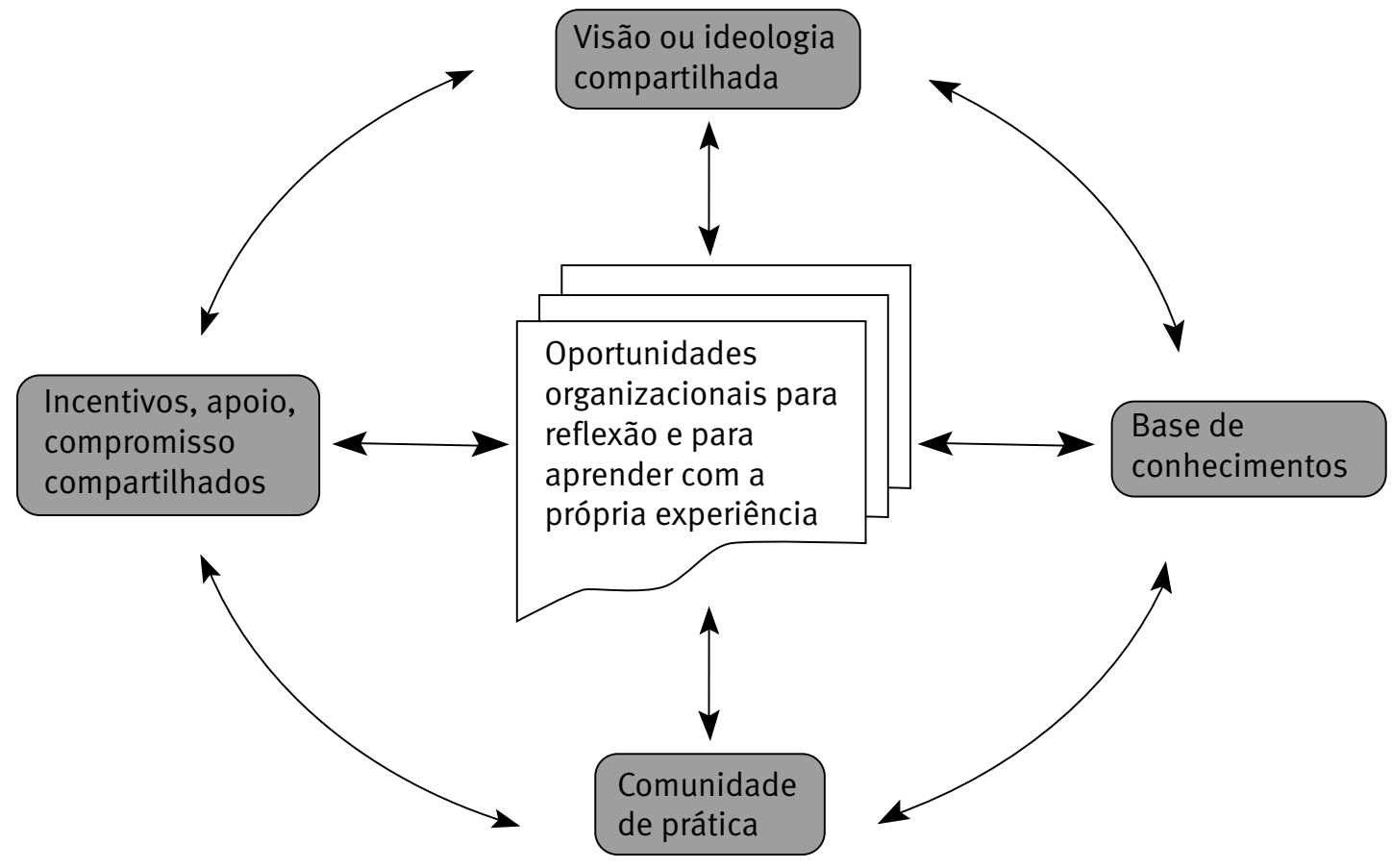

Fonte: Elaborada pelos autores.

Podemos, pois, ver o ensino e o aprendizado do professor em termos de um conjunto de polígonos encaixados, nos quais nosso modelo de Visão, Motivação, Compreensão, Prática e Reflexão é representado de alguma forma em cada camada a partir de uma concepção multifacetada. A camada interna 
(que não aparece aqui) é um modelo de toda aprendizagem, começando com aquela esperada dos alunos na sala de aula de cada professor. Aprendizes de qualquer nível precisam desenvolver uma visão das possíveis compreensões e aprendizagens que podem alcançar, a motivação para buscar e persistir nessa aprendizagem, a compreensão necessária para buscar essa aprendizagem (tanto ímpeto como resultado) e a capacidade de organizar a complexidade da sala de aula para garantir seriedade e organização voltadas ao ensino. Todas essas ações são necessárias para um ensino eficaz. A aprendizagem ocorre com maior eficácia se for acompanhada pela consciência metacognitiva e pela análise do próprio processo de aprendizagem por cada aprendiz, e se for apoiada pela participação numa comunidade de aprendizagem. Com efeito, este modelo pode ser aplicado ao processo de aprendizagem tanto de alunos como de professores.

Figura 3 - Comunidades de aprendizagem nos níveis individual e institucional

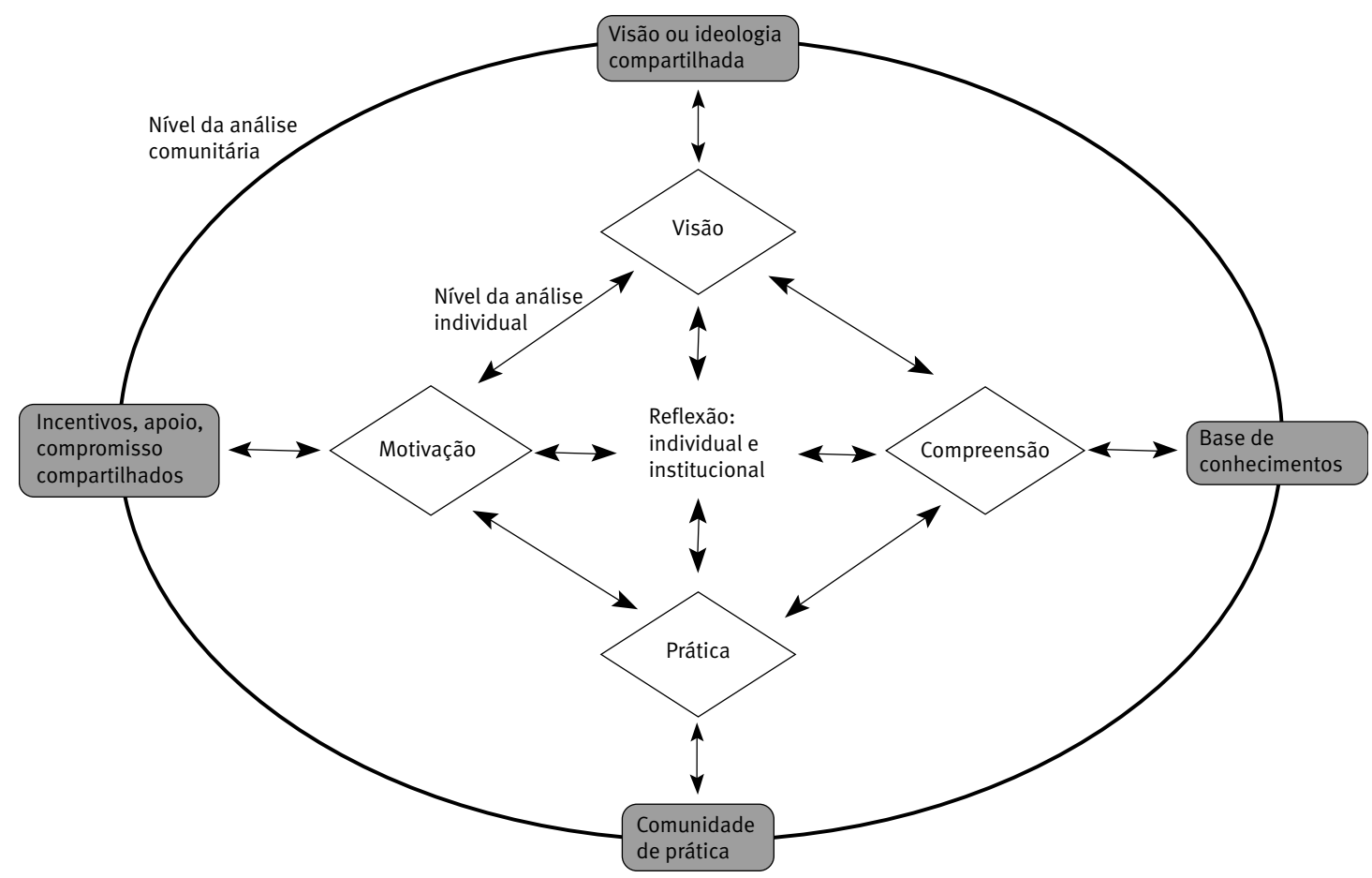

Fonte: Elaborada pelos autores.

Uma outra camada pode ser representada por um modelo para ensinar e aprender a ensinar, dentro de comunidades de professores, tendo estes como aprendizes. Na formação inicial ou continuada de professores, os formadores devem criar ambientes que apoiam, sustentam e "refinam" as visões, as compreensões, as práticas, as motivações e as reflexões de todos os seus membros. Portanto, como ensinou Merton, os níveis individual e comunitário são, ao mesmo tempo, independentes e inter-relacionados. 
A camada mais superficial é a área das políticas públicas. Nessa camada está a alocação de recursos (ver Figura 4). O ensino e a aprendizagem eficazes dependem da provisão de recursos adequados, como tutoria, formação continuada, materiais curriculares e livros didáticos, instrumentos e modelos de avaliação, pessoal de apoio, computadores, espaço físico adequado. A natureza dos recursos curriculares foi de interesse particular para o nosso trabalho específico (o PCPA) porque o professor, como intérprete e adaptador das orientações curriculares, e também como usuário deste currículo, era central nos nossos esforços. A ausência de materiais curriculares adequados, fiéis tanto às expectativas comuns de aprendizagem como às nossas concepções do aprendizado do aluno e da prática em sala de aula, era um obstáculo fatal para o sucesso da reforma PCA. A camada dos recursos pode ser um elemento indispensável para esforços que dependem de mudança na compreensão e nas habilidades dos professores. Escolhemos usar a metáfora do "capital" para definir esses recursos e distinguimos entre capital de risco, que representa a provisão de recursos financeiros e materiais, capital curricular, cultural e moral e capital técnico. Empregamos esses construtos como um lembrete de que estes são contextos e comunidades agregados, e que o mundo da política pública é representado tanto pelo apoio como pela execução das mudanças e inovações em ensino e aprendizagem às quais nos referimos. 
Figura 4 - Comunidades de aprendizagem nos níveis individual e institucional

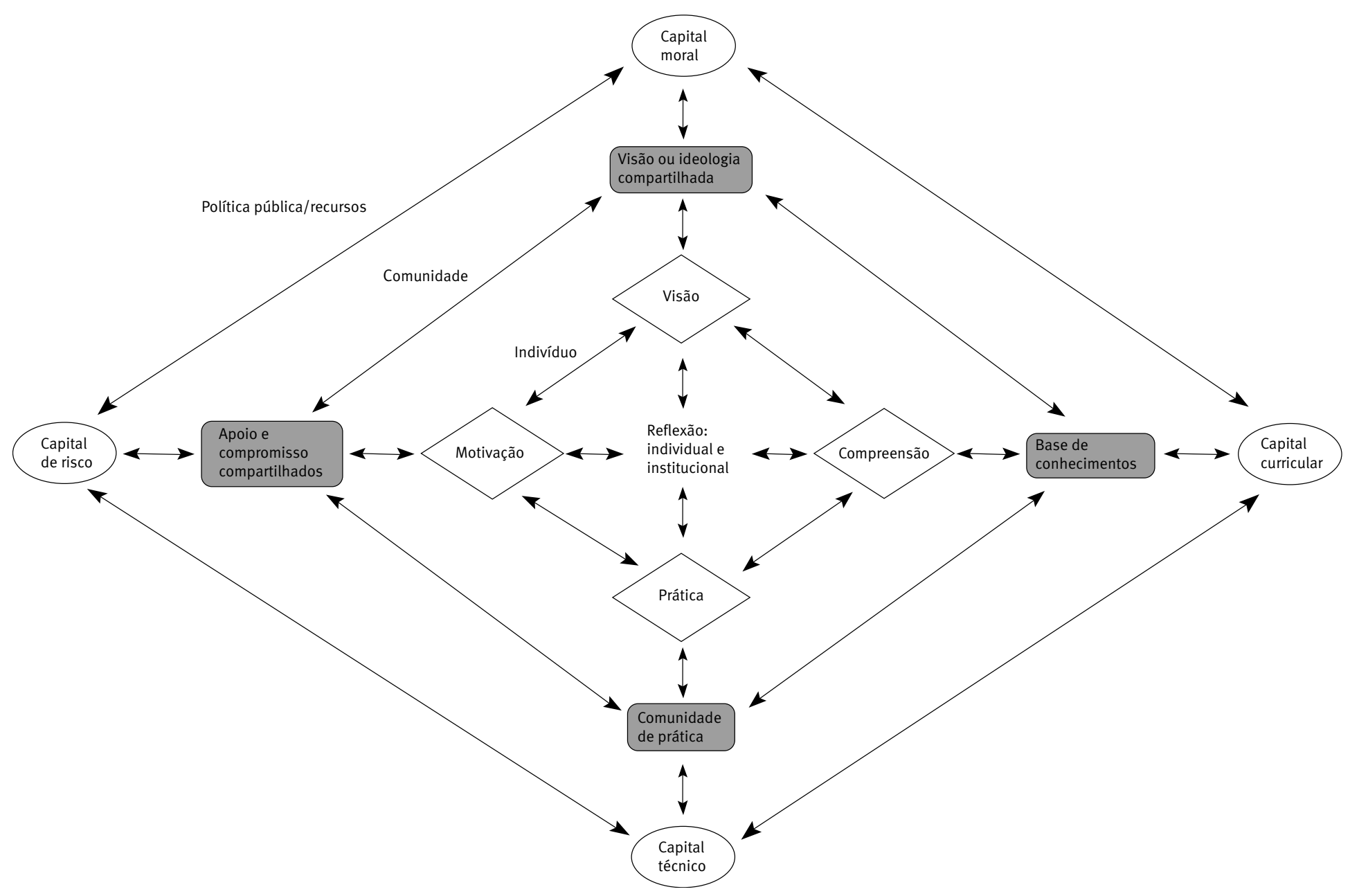

Fonte: Elaborada pelos autores.

Em conclusão, no nosso trabalho, a análise da aprendizagem do professor foi da preocupação com a aprendizagem individual de cada professor para uma concepção de professores aprendendo e se desenvolvendo dentro de um contexto mais abrangente, ou seja, comunidade, instituição, organização política e profissão. Isso, por sua vez, lançou as fundações para um pensamento mais recente sobre os objetivos da aprendizagem de forma geral, para os alunos em diversos contextos e também para os que estão aprendendo uma profissão.

Agora podemos voltar para as especificidades do projeto PCPA e perguntar: o que aprendemos? Como relatado nos artigos precedentes e nos comentários críticos de Gardner (2004) e Schoenfeld (2004), este programa de trabalho trouxe com ele resultados variados. Da perspectiva do ensino e da aprendizagem do professor, tornamo-nos muito mais conscientes da complexidade do aprender a ensinar num contexto de mudança que parte de 
uma teoria. Embora nesse contexto “o conteúdo disciplinar importe”, há tantas coisas acontecendo simultaneamente que, às vezes, as diferenças sempre importantes de conteúdo podem ser atropeladas por outras características críticas do contexto. Mesmo assim, ao reconhecer as limitações tanto do conteúdo quanto do contexto como fatores determinantes da prática e do impacto do professor, foi-nos dada uma oportunidade importante para desenvolver novos modelos analíticos para explorar e analisar como os professores aprendem nessas circunstâncias.

Esperamos que estes modelos de aprendizagem docente, tanto em suas partes constituintes como em suas estruturas, possam ser de valor para nossos colegas que atuam na formação de professores e no desenho das políticas educacionais, à medida que eles exploram as condições sob as quais a melhoria dos programas educacionais pode ocorrer. Oferecemos esses modelos como tentativas de responder à questão do porquê reformas educacionais ambiciosas parecem funcionar com sucesso num cenário e falhar em outros, em todo ou em parte.

Há muitos anos, o economista estadunidense Victor Fuchs descreveu-se como um tipo de cientista social que encontra alguma coisa que funciona na prática e, depois, tenta descobrir se também funciona na teoria. Nossos modelos surgiram de circunstâncias um pouco menos reconfortantes. Nós confrontamos fenômenos que não funcionam na prática exatamente como planejados e tentamos fazê-los funcionar na teoria. E, se não funcionassem nem na teoria, que pelo menos gerassem alguns modelos teóricos que pudessem iluminar nossos colegas que, no futuro, venham a projetar, diagnosticar ou explicar esforços na área de formação de professores de maneira eficaz e mais conscientes de seu papel.

\section{EM SÍNTESE}

De muitas maneiras, este foi o programa de pesquisa-ação mais desafiador, frustrante e, mesmo assim, esclarecedor que qualquer um de nós jamais conduziu. Não podemos afirmar que, por meio deste trabalho, demonstramos como formar professores para ensinar num ambiente compativel com o PCA. Nesse sentido, falhamos. No entanto, aprendemos muita coisa que pode ser aplicada em outros contextos, especialmente naqueles em que as exigências aos professores sejam menos desafiadoras do que as colocadas pelo PCA. 


\section{AGRADECIMENTOS}

Esta pesquisa foi financiada com recursos da Fundação Andrew W. Mellon para a Universidade Stanford e da WestEd para o Projeto Promover uma Comunidade de Professores Aprendizes, tendo Lee S. Shulman e Judith $\mathrm{H}$. Shulman como principais pesquisadores. As opiniões aqui expressas são dos autores e não refletem necessariamente a visão das agências de apoio. 


\section{How and What Teachers Learn: A Shifting Perspective}

Abstract: Based on the experience of the "Fostering a Community of Learners" (FCL) program, this article proposes a conceptual framework to deepen understanding about the ways in which teachers learn and, particularly, the ways in which they learn to teach in different communities and contexts. In presenting a new model, we aim to reflect critically about the challenges facing teachers, teacher communities, teacher education institutions, programs and policies centered on teacher professional development.

Keywords: Teacher education. Educational policy. Teaching. Didactics. 


\section{Cómo y qué aprenden los profesores: una perspectiva en transformación}

Resumen: A partir de la experiencia del programa "Promover una comunidad de aprendices", se propone en este artículo una estructura conceptual para profundizar la comprensión sobre los distintos modos de aprender, en general, de los profesores $y$, en particular, de aprender a enseñar en diferentes comunidades y contextos. Al presentar un nuevo modelo, se busca reflexionar críticamente sobre los desafíos encontrados por los profesores, las comunidades de profesores, las instituciones formadoras y los programas y políticas que se centran en el desarrollo profesional docente.

Palabras clave: Formación de profesores. Política educacional. Enseñanza. Didáctica. 


\section{REFERÊNCIAS}

BROWN, A. L.; CAMPIONE, J. C. Fostering a community of learners: a proposal submitted to the Andrew W. Mellon Foundation. Berkeley: Universidade da Califórnia, 1992.

; . Psychological theory and the design of innovative learning environments: on procedures, principles, and systems. In: SCHÄUBLE, L.; GLASER, R. (Eds.). Innovations in Learning: New Environments for Education. Mahwah, NJ: Erlbaum, 1996. p. 289-325.

COHEN, D. K. A revolution in one classroom: the case of Mrs. Oublier. Educational Evaluation and Policy Analysis, v. 12, n. 3, p. 311-329, 1990.

GARDNER, H. Discipline, understanding, and community. Journal of Curriculum Studies, v. 36, n. 2, p. 233-236, 2004.

HAMMERNESS, K. Seeing Through Teachers' Eyes: Professional Ideals and Classroom Practices. Nova York: Teachers College Press, 2006.

JOURNAL OF CURRICULUM STUDIES. ISSN 0022-0272 impressa/ISSN 13665839 on-line, Taylor \& Francis Ltd., 2004. Disponível em: 〈http://www. tandf. co.uk/'journals〉. DOI: 10.1080/0022027032000148298.

MERTON, R. On Theoretical Sociology: Five Essays, Old and New. Nova York: Free Press, 1967.

MINTROP, $\mathrm{H}$. Fostering constructivist communities of learners in the amalgamated multi-discipline of social studies. Journal of Curriculum Studies, v. 36, n. 2, p. 141-158, 2004.

NATIONAL BOARD FOR PROFESSIONAL TEACHING STANDARDS. What Teachers Should Know and Be Able To Do. Arlington, VA: National Board for Professional Teaching Standards, 1992.

RICO, S. A.; SHULMAN, J. H. Invertebrates and organ systems: science instruction and "Fostering a Community of Learners". Journal of Curriculum Studies, v. 36, n. 2, p. 159-181, 2004.

SCHOENFELD, A. H. Multiple learning communities: students, teachers, instructional designers, and researchers. Journal of Curriculum Studies, v. 36, n. 2, p. 237-255, 2004. 
SHERIN, M. G. Developing a professional vision of classroom events. In: WOOD, B.; NELSON, S.; WARFIELD, J. (Eds.). Beyond Classical Pedagogy: Teaching Elementary School Mathematics. Hillsdale, NJ: Erlbaum, 2001. p .75-93.

; HAN, S. Teacher learning in the context of a video club. Teaching and Teacher Education: An International Journal of Research and Studies, v. 20, n. 2, p. 163-183, 2004.

; MÉNDEZ, E. P; LOUIS, D. A. A discipline apart: the challenge of "Fostering a Community of Learners" in a mathematics classroom. Journal of Curriculum Studies, v. 36, n. 2, p. 207-232, 2004.

SHULMAN, J. H. Happy accidents: cases as opportunities for teacher learning. In: ENCONTRO ANUAL DA ASSOCIAÇÃO AMERICANA DE PESQUISA EM EDUCAÇÃO, 2002, Nova Orleans. Anais... Nova Orleans, WestEd, 2002.

From practice to theory and back again: cases and portfolios as instruments for professional development. In: ENCONTRO ANUAL DA ASSOCIAÇÃO AMERICANA DE PESQUISA EM EDUCAÇÃO, 2003, Chicago. Anais... Chicago, WestEd, 2003.

; MEYER, R. T.; MOFFETT, K. (Eds.) Fostering a Community of Teachers as Learners: A Casebook for Educators. Palo Alto, CA: Universidade Stanford/ WestEd, 1997. v. 6.

SHULMAN, L. S. Those who understand: knowledge growth in teaching. Educational Researcher, v. 15, n. 2, p. 4-14, 1986.

. Knowledge and teaching: foundations of the new reform. Harvard Educational Review, v. 57, n. 1, p. 1-22, 1987.

WHITCOMB, J. A. Dilemmas of design and predicaments of practice: adapting the "Fostering a Community of Learners" model in secondary school English language arts classrooms. Journal of Curriculum Studies, v. 36, n. 2, p. 183206, 2004. 
LEE S. SHULMAN é professor aposentado da Universidade de Stanford, onde é professor emérito -- cátedra Charles E. Ducommun -- da Escola de Educação. Foi presidente da Associação Americana de Pesquisa Educacional, da Academia Nacional de Educação, e da Fundação Carnegie para o Avanço do Ensino.

shulman@stanford.edu

JUDITH H. SHULMAN dirigiu o Instituto para Desenvolvimento de Estudos de Casos e a Rede de Apoio ao Conselho Nacional para Padrões Profissionais de Ensino na WestEd. 